\title{
YOUTUBE E EDUCAÇÃO: UMA REVISÃO DA PESQUISA BRASILEIRA NO PERÍODO DE 2014 A 2021
}

\author{
Mirian Raquel Buiz Mion - UFRGS/PGIE - buizmion@ @otmail.com, \\ https://orcid.org/0000-0002-7629-5330 \\ Daniel de Queiroz Lopes - UFRGS/PGIE - daniel.lopes@ufrgs.br, \\ https://orcid.org/0000-0002-0560-0385
}

\begin{abstract}
Resumo: As reflexões apresentadas neste artigo resultam de uma pesquisa bibliográficadocumental acerca de estudos que apresentam ou problematizam o YouTube como uma tecnologia educacional. Neste âmbito, foram analisados 20 trabalhos, entre artigos e dissertações, publicados no Brasil entre os anos de 2014 e 2021, tendo como eixo condutor dessa análise a questão "O que dizem as pesquisas sobre o YouTube e a Educação?" Tal recurso já vinha sendo utilizado na educação em função do seu apelo audiovisual, mesmo antes da pandemia, pois sua linguagem se aproxima mais da juventude contemporânea, proporcionando autoria e protagonismo docente e discente. Ainda o artigo aponta que é necessário ressaltar a necessidade de maior diálogo com a área da comunicação e da linguagem em relação à produção de conteúdo audiovisual e à educação na cultura digital.
\end{abstract}

Palavras-chave: YouTube, Educação, Ensino, Docência Online.

\section{YOUTUBE AND EDUCATION: A REVIEW OF BRAZILIAN RESEARCH FROM 2014 TO 2021}

Abstract: The observations presented in this article are the outcome of a bibliographicdocumental research about studies that present or problematize YouTube as an educational tool. In this context, 20 studies were analyzed, including articles and dissertations published in Brazil between 2014 and 2021, having the question "What does the research on YouTube and Education say?" as the guiding principle of such analysis. This resource had already been used in education due to its audiovisual appeal, even before the pandemic, as its language is closer to contemporary youth, providing authorship and protagonism for teachers and students. The article also points out that it is necessary to emphasize the need for greater dialogue between the area of audiovisual content production related to communication and language and the sector of education in digital culture.

Keywords: YouTube, Education, Teaching, Online Teaching.

\section{Introdução}

As reflexões apresentadas neste $\operatorname{artigo}^{[\mathrm{a}]}$ resultam de uma pesquisa bibliográficadocumental acerca de trabalhos que apresentam ou problematizam o YouTube como uma tecnologia educacional. Encontramos farto material de pesquisa dedicado a analisar o potencial do YouTube para as aprendizagens. Essas pesquisas, no entanto, como veremos mais adiante, raramente dialogam de forma mais direta com as teorias da comunicação e da linguagem. Ao desconsiderarem esse diálogo, não problematizam conceitos chave para o contexto das pesquisas em educação e cultura digital que têm sido importantes para se V. $19 \mathrm{~N}^{\mathrm{o}}$ 2, Dezembro, 2021 RENOTE 
entender o leitor contemporâneo, que possui um regime de atenção e leitura de imagens agregadora diferente dos leitores de outrora.

Para o universo das teorias da comunicação, temos que considerar que o YouTube, junto com as demais mídias digitais sociais, tem se demonstrado como um importante suporte contemporâneo de comunicação, ficando mais evidente durante a Pandemia de Covid-19.

Um dos caminhos para a compreensão das apropriações tecnológicas relacionadas às aprendizagens, no contexto da cultura digital, passa pela necessidade de compreender como essas apropriações têm ocorrido ao longo da história. Considerando as transformações tecnológicas e subjetivas relacionadas aos dispositivos de leitura ao longo do tempo, uma indagação que se apresenta é se a produção de conteúdo audiovisual com o objetivo de ensinar tem levado em consideração esses elementos característicos do leitor contemporâneo. Dessa forma, no presente estudo, os trabalhos que relacionam o YouTube com a educação são aqui analisados no sentido de perceber como se têm entendido a contribuição do YouTube na educação formal, ao mesmo tempo em que se problematizam os resultados dessas pesquisas na perspectiva do diálogo com o que propõe Santaella (2013, 2014) sobre o leitor contemporâneo.

A partir de um levantamento bibliográfico, que compreende o período de 2014 a 2021, propomos algumas reflexões sobre o que os resultados das pesquisas apontam em relação ao uso educacional do YouTube. Como eixo condutor deste artigo, temos a questão: $O$ que dizem as pesquisas sobre o YouTube e a Educação? A intenção deste trabalho, portanto, é problematizar, a partir de estudo bibliográfico, as diferentes abordagens de pesquisas brasileiras sobre o tema YouTube e Educação em relação aos aspectos comunicacionais que envolvem essas tecnologias, tendo como eixo transversal de análise a ideia de leitor contemporâneo, como traço característico dos leitores inseridos em uma cultura digital.

\section{Percurso Metodológico}

O procedimento adotado para nos aproximarmos das pesquisas envolvendo YouTube e Educação deu-se através dos indexadores Google Scholar (Google Acadêmico) e o Catálogo de Teses e Dissertações da Capes (CTDC), realizados durante o período de novembro de 2019 a junho de 2021. As buscas consideraram os últimos sete anos, abarcando, portanto, o período pré-pandêmico, assim como o pandêmico, circunscritos à produção acadêmica brasileira. O presente estudo está inserido no contexto de uma pesquisa mais abrangente sobre a midiatização como estratégia para a docência online, iniciada em 2019. Durante o período de delineamento do campo desta pesquisa, foram realizadas a busca e a leitura de artigos que dessem conta dos conceitos pesquisados, tendo como string de busca genérico: YouTube AND (educação OR ensino). O Google Scholar foi selecionado como ferramenta de busca por permitir acesso mais abrangente a textos acadêmicos, buscando referências em diversas bases de documentos disponíveis online. Já o CTDC foi escolhido por nos permitir obter um panorama mais diretamente relacionado à pós-graduação no Brasil, no sentido de conhecer como está a produção científica sobre o tema nos diferentes grupos de pesquisa brasileiros.

O passo seguinte foi estabelecer os critérios de inclusão e exclusão, conforme o Quadro 1. O espaço temporal de pesquisa foi o primeiro critério de inclusão que foi considerado, sendo estabelecido o período entre 2014 a 2021. Selecionou-se esse espaço de tempo devido à necessidade de buscar dados mais recentes sobre o uso dessa plataforma na educação. Também foi nesse período, mais precisamente no segundo semestre de 2013, que foi lançado o canal "YouTube Edu", contexto onde se desenrola a V. $19 \mathrm{~N}^{\circ}$ 2, Dezembro, 2021 DOI: https://doi.org/10.22456/1679-1916.121376 RENOTE 
pesquisa principal a qual está vinculada este artigo. Os outros dois critérios de inclusão aplicados foram conter no título do trabalho a palavra "YouTube" e informar em seus resumos que se tratava de uma pesquisa envolvendo a participação de professores/pesquisadores no uso do YouTube integrado ao ensino formal. Esses critérios se justificam em função de que essa pesquisa bibliográfica cumpria uma das etapas de uma pesquisa mais ampla envolvendo a docência online. Dessa forma, foram excluídos trabalhos ou experiências isoladas ou informais limitadas à aprendizagem de produção de vídeos por estudantes ou outros coletivos. Após a aplicação desses critérios, resultaram para leitura em profundidade 20 publicações, das quais 15 são artigos e 5 são dissertações de mestrado.

Quadro 1 - Critérios de inclusão/exclusão das pesquisas analisadas

\begin{tabular}{|l|l|l|l|}
\hline Critério & Google acadêmico & CTDC & Geral \\
\hline $\begin{array}{l}\text { 1-Busca a partir dos descritores } \\
\text { "YouTube" AND ("educção" } \\
\begin{array}{l}\text { OR "ensino") com filtro "Ano" } \\
\text { de 2014 a 2021 (número de }\end{array}\end{array}$ & 23200 & 85 & 23285 \\
\hline $\begin{array}{l}\text { 2-Relevância } \\
\text { citações dos trabalhos, contidos } \\
\text { nas 10 primeiras páginas da busca } \\
\text { no Google Acadêmico) }\end{array}$ & 100 & $85^{*}$ & 185 \\
\hline $\begin{array}{l}\text { 3-Foco na temática - inclusão da } \\
\text { palavra YouTube no título }\end{array}$ & 27 & 9 & 36 \\
\hline $\begin{array}{l}\text { 4-Foco na temática da docência } \\
\text { no ensino formal informada nos } \\
\text { resumos }\end{array}$ & 15 & 5 & 20 \\
\hline $\begin{array}{l}\text { Total de pesquisas analisadas em profundidade } \\
\text { Fonte: Elaborado pelos autores (2021) }\end{array}$ & $\mathbf{2 0}$ \\
\hline
\end{tabular}

\section{Análise dos Resultados}

Para dar conta de responder a pergunta central " $O$ que dizem as pesquisas sobre $O$ YouTube e a Educação?" as análises dos textos revelaram, em termos gerais, que essa tecnologia audiovisual tem proporcionado aos professores outras possibilidades de ensino, que brevemente apresentaremos no Quadro 2 e nas análises a seguir.

Inicialmente, a pesquisa nos apresentou textos sobre experiências relacionadas às apropriações do YouTube para o ensino. Quintanilha (2017) e Pechansky (2016) propõem que essa plataforma de compartilhamento tem servido como estratégia de utilização de vídeos no sentido da aproximação com os alunos, em especial com aqueles que são identificados como uma geração que está imersa nas tecnologias audiovisuais, os da geração "Z" ou "nativos digitais", que são os jovens nascidos na era da Internet. As pesquisas desses autores dialogam indiretamente com o que Santaella (2013) descreve sobre essa geração dos nativos digitais que são os leitores contemporâneos e que se sentem à vontade em conviver com as mídias digitais, fazendo parte do dia a dia pessoal e escolar, possibilitadas pela mobilidade no acesso à informação. Além disso, os resultados dessas pesquisas reforçam o entendimento de que o traço geracional tem sido, frequentemente, apresentado como justificativa por parte dos professores para que suas propostas pedagógicas tenham maior aceitação - no sentido motivacional - e compreensão pelos estudantes. Esse entendimento já estava presente nas pesquisas sobre mídias na educação, ainda num contexto das tecnologias massivas, como a TV, o rádio e a imprensa. De fato, à compreensão já estabelecida, de que existe a necessidade de 
adequação da linguagem dos materiais didáticos e propostas pedagógicas às diferentes faixas etárias, acrescenta-se a necessidade de se compreender mais amplamente o fenômeno comunicacional e informacional que surge no contexto pós-massivo.

Quadro 2 - Relação de pesquisas analisadas em profundidade

\begin{tabular}{|c|c|c|}
\hline $\begin{array}{l}\text { Autores dos trabalhos (Ano de } \\
\text { publicação) }\end{array}$ & $\begin{array}{l}\text { Quantidade } \\
\text { de trabalhos }\end{array}$ & Ideia principal \\
\hline $\begin{array}{l}\text { 1. Quintanilha (2017); } \\
\text { 2. Pechansky (2016) }\end{array}$ & 2 & $\begin{array}{l}\text { YouTube como estratégia para aproximação com os alunos (nativos digitais); } \\
\text { apelo audiovisual. }\end{array}$ \\
\hline $\begin{array}{l}\text { 3. Silva, Pereira e Arroio } \\
\text { (2017) }\end{array}$ & 1 & $\begin{array}{l}\text { YouTube pode proporcionar "ganho cognitivo" ao proporcionar a diversidade de } \\
\text { informações; também se aproxima da linguagem dos jovens (leitor ubíquo). }\end{array}$ \\
\hline 4. Roskowinski (2016) & 1 & $\begin{array}{l}\text { YouTube, por si só, não caracteriza inovação; necessidade de planejamento para } \\
\text { dar conta do "letramento digital" de professores e alunos. }\end{array}$ \\
\hline 5. Santana (2018) & 1 & $\begin{array}{l}\text { YouTube aumenta a carga de trabalho; mas aumenta o protagonismo e } \\
\text { habilidades de docentes e discentes. }\end{array}$ \\
\hline $\begin{array}{l}\text { 6. Coelho e Bottentuit Jr. } \\
\text { (2019); } \\
\text { 7. Rebelo e Carvalho (2017) }\end{array}$ & 2 & $\begin{array}{l}\text { YouTube como recurso para ampliar a capacidade crítica, a reflexão e } \\
\text { potencializar a habilidade de pesquisa e compartilhamento de experiências; } \\
\text { auxilia na construção do conhecimento. }\end{array}$ \\
\hline $\begin{array}{l}\text { 8. Kamigouchi (2017); } \\
\text { 9. Bispo e Barros (2016); } \\
\text { 10. Neto e De Sá (2019); } \\
\text { 11. Oliveira, J. (2016); } \\
\text { 12. Queiroga Jr. e Dulci } \\
\text { (2019); } \\
\text { 13. Souza, et al (2019) }\end{array}$ & 5 & $\begin{array}{l}\text { YouTube como recurso para o ensino de história; problematiza o papel da } \\
\text { docência na formação do sujeito. }\end{array}$ \\
\hline 14. Junges e Gatti (2019) & 1 & $\begin{array}{l}\text { YouTube favorece a autoria, a autonomia, a tomada de decisão, a criatividade, a } \\
\text { criação de uma estética própria, um currículo participativo. }\end{array}$ \\
\hline 15. Oliveira, P.P.M (2016) & 1 & YouTube como recurso para a autoria docente e discente. \\
\hline 16. Brito Silva (2019) & 1 & $\begin{array}{l}\text { YouTube como possibilidade de construção e socialização de conhecimentos; } \\
\text { modo criativo de ensinar, como alternativa às aulas expositivas. }\end{array}$ \\
\hline 17. Silva, M. (2017) & 1 & $\begin{array}{l}\text { YouTube como possibilidade de reflexão de como as disciplinas têm sido } \\
\text { trabalhadas na sala de aula e a dinâmica entre esse espaço real e o processo de } \\
\text { ensino e aprendizagem virtual por meio dos vídeos. }\end{array}$ \\
\hline 18. Paulo, P. (2017) & 1 & Material inclusivo no YouTube auxilia várias disciplinas. \\
\hline $\begin{array}{l}\text { 19. Borges (2020) } \\
\text { 20. De Mello Souza (2020) }\end{array}$ & 2 & $\begin{array}{l}\text { O uso do YouTube como nova abordagem no processo de ensino e aprendizagem } \\
\text { no tempo da cibercultura. }\end{array}$ \\
\hline Total: & 20 & \\
\hline
\end{tabular}

Fonte: Elaborado pelos autores (2021)

Silva, Pereira e Arroio (2017), ao investigarem o uso de vídeos relativos às Ciências Naturais por estudantes no ensino médio, descobriram que o perfil dos jovens que usam o YouTube para estudar é caracterizado pela habilidade de gerenciar múltiplas informações nos diferentes canais que acessam, e que trazer essa habilidade para o campo das aprendizagens poderia acarretar "ganho cognitivo". Também nesse caso é possível estabelecer relação com o que propõe Santaella (2013), que afirma que essa característica é própria dos leitores contemporâneos que transitam por várias telas. No entanto, é preciso caracterizar melhor a compreensão do que seriam esses "ganhos cognitivos". Apesar das 
transformações proporcionadas pelos dispositivos multimidiáticos de leitura contemporâneos, no campo da pesquisa sobre aprendizagem não há unanimidade em relação aos seus benefícios, principalmente quando se trata de crianças pequenas ${ }^{[\mathrm{c}]}$.

Para Coelho e Junior (2019), a utilização dos vídeos do YouTube auxilia na construção de novos conhecimentos adquiridos através da experiência de utilizar esse recurso para ampliar a capacidade crítica, a reflexão e potencializar a habilidade da pesquisa, assim como o compartilhamento de experiências. No mesmo sentido, Rebelo e Carvalho (2017) analisam se a publicação dos conteúdos nesses canais online contribui para a construção de novos conhecimentos, e concluem que o uso do YouTube auxilia nesse processo.

Como um dos achados desta pesquisa, a disciplina de história foi a área do conhecimento mais explorada nos trabalhos pesquisados. A apropriação do YouTube, como recurso para ensinar história, foi tema do artigo proposto por Kamigouchi (2017), assim como Bispo e Barros (2016), Neto e De Sá (2019), Souza et al (2019), Queiroga e Dulci (2019) e Oliveira (2016). Para eles, as mídias sociais digitais têm um papel importante na formação do sujeito e refletir sobre isso é também problematizar o papel da docência. Buscam, assim, pensar o ser professor de história frente ao ensino desta disciplina, ora como contribuição, ora como obstáculo.

Outro tema importante que se destacou na pesquisa bibliográfica realizada foi o da autoria docente. Junges e Gatti (2019) mostram em seu estudo, que os recursos midiáticos possibilitam o desenvolvimento de habilidades e competências relacionado à autoria, à autonomia, à tomada de decisão, à criatividade, à criação de uma estética própria, além da participação na constituição dos currículos. No entanto, a midiatização da docência passa pela necessidade dos professores se apropriarem dos recursos que as plataformas oferecem. Assim, como sustenta Oliveira, P. P. M. (2016), a autoria docente é uma das possibilidades suscitadas pelas plataformas de veiculação de vídeos. A pesquisa do autor teve como objetivo demonstrar a utilização de vídeos do YouTube como ferramenta pedagógica. A autoria proporcionada pela apropriação da plataforma não diz respeito apenas aos docentes, mas também aos discentes que também podem socializar seus conhecimentos, assim como toda a comunidade que possui acesso a essa tecnologia. Também Santana (2018) alerta que o YouTube aumenta a carga de trabalho, mas também aumenta o protagonismo e habilidade docente e discente. Contrapondo esse sentindo, Roskowinski (2016) ressalta que o YouTube, por si só, não caracteriza inovação; há a necessidade de se fazer planejamento para dar conta do "letramento digital" de professores e alunos.

Foi possível identificar, a partir da análise dos artigos mais recentes, que houve um aumento significativo no YouTube de materiais com conteúdo educacional no período pandêmico. Segundo De Mello Souza (2020) houve um aumento de 140\% de canais voltados a conteúdo de ciências, por exemplo. Tal fato pode ser explicado em função da suspensão das aulas presenciais em todo o país. Para contornar a situação, o Conselho Nacional de Educação liberou a utilização da Internet como meio de ministrar aulas online, feitas por videoconferências, além de Ambientes Virtuais de Aprendizagem (AVAs) em todos os níveis do ensino formal. E em Borges (2020) há o entendimento de que esta plataforma é um espaço público educador, potencializado pela possibilidade de ouvir e ser ouvido.

Fechando o contexto nas análises das pesquisas, encontramos alguns trabalhos na forma de dissertação que ainda merecem referência, como o trabalho de Silva (2017), intitulado "O uso de vídeos no ensino de ciências: o papel do YouTube para estudantes do ensino médio", que avalia o papel da plataforma no ensino e aprendizagem presencial e virtual; a dissertação de Silva (2016), com o título "YouTube, juventude e escola em 
conexão: a produção da aprendizagem ciborgue", que versa sobre que tipo de aprendizagem está sendo formada com o advento das tecnologias, que seria para o autor aprendizagem ciborgue; o trabalho de Paulo (2017), intitulado "Produção de videoaulas como materiais didáticos inclusivos para professores de química no ensino médio", que versa sobre o ganho para todas as disciplinas de incluir material inclusivo através do YouTube; a dissertação de J. Silva (2019), a "Plataforma YouTube como ferramenta para o ensino de biologia", que versa sobre a importância do uso da plataforma na busca de conhecimento e a dissertação de Brito (2019), intitulada "Plataforma YouTube® como ferramenta para o ensino de Biologia", que versa sobre como a tecnologia auxiliaria no processo de aulas mais criativas.

\section{Discussão e Considerações Finais}

Este artigo analisou o que pesquisas acadêmicas publicadas no período de 2014 a 2021 têm revelado sobre o YouTube e a Educação. A partir das bases de dados consultadas, encontramos, diante das publicações analisadas, que o uso do YouTube, como possibilidade pedagógica, possibilitaria aulas mais atrativas e que motivariam professores que se valem de vídeos para complementar suas aulas, utilizando a tecnologia como uma aliada pedagógica. Esse movimento de apropriação das tecnologias, no período pré-pandêmico, tinha como sentido aproximar as atividades educacionais do universo jovem e conectado, caracterizado como um leitor contemporâneo. Porém, para além de simplesmente considerar essa característica como um demarcador geracional que aponta diferenças, é necessário compreendê-la como um fenômeno social da contemporaneidade, cujo entendimento pode ampliar as possibilidades e adequar estratégias e repertório comunicacional da docência. Todavia, durante o período da pandemia, o que se mostrava nos artigos pré-pandêmicos como uma alternativa, virou uma possibilidade, transformando o que até então era apenas uma estratégia educacional para capturar leitores contemporâneos, em uma necessidade que se impunha a todos os tipos de leitores.

A partir das análises das pesquisas sobre YouTube e Educação, foi possível constatar que há pouco diálogo efetivo com as contribuições das teorias do campo da comunicação e da linguagem (Quadro 3). Abaixo constam os principais autores e conceitos operados nas pesquisas analisadas.

Quadro 3 - Relação de principais autores e conceitos operados nos textos analisados

\begin{tabular}{|l|l|}
\hline Principais Autores & Principais conceitos operados \\
\hline P. LEVY & Inteligência coletiva/Cibercultura \\
\hline N. BERBEL; P. FREIRE & Autonomia do estudante \\
\hline $\begin{array}{l}\text { J. MORÁN; N. PRETTO; J. A MOREIRA; A. } \\
\text { MONTEIRO; M. G. NOGUEIRA. \& M. A. PADILHA }\end{array}$ & Tecnologias na educação \\
\hline J. RÜSEN & Consciência histórica \\
\hline M. YUNUS \& H. SALEHI & $\begin{array}{l}\text { Uso de redes sociais para estudos de } \\
\text { línguas }\end{array}$ \\
\hline J. BURGUESS \& J. GREEN & YouTube \\
\hline J. PACHECO & Metodologias ativas \\
\hline A. PRIMO & Arquitetura de participação \\
\hline S. HALL & Cultura \\
\hline D. HARAWAY & Ciborgue \\
\hline J. DAYRELL; SILVA e SILVA; M. SPOSITO & Juventude \\
\hline H. PERRATON & Educação a distância \\
\hline SILVA, PEREIRA e ARROIO & Protagonistas de saberes \\
\hline
\end{tabular}




\begin{tabular}{|l|l|}
\hline Principais Autores & Principais conceitos operados \\
\hline M. BAKTHIN & Gêneros discursivos \\
\hline A. SANT'ANNA & Discursos publicitários \\
\hline $\begin{array}{l}\text { R. RECUERO; L. SANTAELLA; C. COLL; A. A. } \\
\text { MARCHESI; J. PALACIOS, }\end{array}$ & Mídia social e redes sociais na Internet \\
\hline J. FERRÉS & Vídeo e Educação \\
\hline R. R. S. SCUCUGLIA & Performance Matemáticas digitais \\
\hline H. GARDNER & Teoria das Inteligências Múltiplas \\
\hline Fonte: Elaborado pelos autores (2021) & \\
\hline
\end{tabular}

O campo da pesquisa envolvendo a cibercultura e a comunicação conta com diversos autores importantes. Trazê-los todos para essa discussão extrapolaria o espaço desta publicação. Dessa forma, após análise dos autores e conceitos trabalhados nos textos, optamos por trazer para o presente artigo o tema do leitor contemporâneo, por entendermos que possui uma potência interdisciplinar para os estudos envolvendo a educação e a cibercultura.

Compreender o leitor contemporâneo passa pelo entendimento de que as relações estabelecidas entre texto e imagem foram se complexificando, desde as figuras e textos escritos em livros, até chegar à leitura de imagens, som, movimento e instantaneidade das mídias sociais digitais. Os repositórios de vídeos, como o YouTube, "escancaram a nossa vida cotidiana e alteram as trocas em sociedade, e, por consequência, em sala de aula" (SANTAELLA, 2014, p. 28). Para aprofundar essa compreensão, a autora consagra, primeiramente, três tipos de leitores: o leitor contemplativo (baseado na leitura do impresso), o leitor movente (iniciado na cultura massiva da televisão, rádio e jornal) e o leitor imersivo (letrado no mundo eletroeletrônico).

O leitor contemplativo é essencialmente o que surge na era pré-industrial, a partir do século XVI, apoiado nos livros impressos com figuras estanques. Esse tipo de leitor utilizava a sua atenção para focalizar nas histórias narradas nos livros que aguçavam a imaginação e prendiam a atenção, pois necessitava muita vigilância, fazendo com que a sua imaginação atuasse de forma mais protagonista, como descreve Santaella (2013).

Para a autora, o capitalismo nos séculos seguintes complexificou a vida cotidiana e, com o surgimento das metrópoles, o tempo, que antes era um elemento insignificante, acelerou. A partir desse cenário surge um novo tipo de leitor, que Santaella nomeia como movente. Passamos, então, do fixo, despreocupado com o tempo e concentrado, para um leitor distraído, interessado em novidades, de memória curta, mas atento ao transcorrer do tempo e lidando com signos que os perseguem aonde quer que ele vá. Nesse momento da história, o entretenimento passa a ter outra relevância na sociedade, que vê surgir, ter sua ascensão e auge através da televisão e do rádio. Eles ascenderam no ambiente da indústria cultural, tomaram proporções significativas graças às tecnologias de difusão, e se tornaram responsáveis pela chamada cultura de massas, que se alastrou, significativamente, graças à transmissão via satélite.

O terceiro tipo de leitor é o imersivo, que surge e ascende a partir das tecnologias eletroeletrônicas. Esse tipo de leitor vive de navegar na internet, buscar algo preciso e explorar até encontrar a informação. Perambulando pelo ciberespaço, conecta-se com múltiplas linguagens, sejam elas escritas, imagéticas, musicais ou audiovisuais. Geralmente de forma transitória, aproveita-se da sua capacidade associativa. Cognitivamente, esse leitor está sempre com a sua atenção em nível de prontidão, o que o faz conectar-se rapidamente com as multimodalidades informativas, formando esse labirinto de caminhos que levam para diversos lugares que estão disponíveis a ele. "Essas tecnologias são chamadas de tecnologias do disponível, que mesclam o apogeu da cultura de massas com o surgimento da cultura digital ou cultura pós-massiva." (SANTAELLA, 2013, p. 287) 
Assim, a mesma autora afirma que ao resultado dessa efervescência, e à recente cultura de participação, soma-se um quarto tipo de leitor: o ubíquo, um leitor que nasceu no âmbito da Web 1.0 e se constituiu na Web 2.0, fruto das conquistas tecnológicas da internet de banda larga e dos dispositivos móveis, ou como podemos chamar, as tecnologias da conexão contínua. O leitor ubíquo herdou características das outras categorias de leitor, passando a ler a realidade através de sinais e tendo a necessidade de mudar de velocidade e de posição. Esse leitor deixa de ser apenas consumidor para também ser produtor de mensagens, tornando-se assim o prossumidor ${ }^{[\mathbf{b}]}$. O ubíquo usa telas que requerem uma atenção parcial contínua, pois está fixado em vários pontos ao mesmo tempo, sem se fixar totalmente. Esse tipo de leitor emerge do mundo informacional e ganha mobilidade graças aos dispositivos móveis, possibilitando subjetivamente se desfazer do espaço fixo, aproveitando-se das modalidades de presença física e digital virtual, tornando-se onipresente através das múltiplas interfaces que se atualizam nas telas dos dispositivos conectados à internet.

A utilização de vídeos e da comunicação audiovisual como alternativas para uma docência online traz para o processo de ensino e aprendizagem o desafio em considerar como o protagonismo e a autoria docente podem se beneficiar dessa compreensão do leitor contemporâneo, trazida por Santaella. Ao dividir o espaço com outros pontos de vistas apresentados pela diversidade de narrativas audiovisuais disponíveis na Internet, o professor pode se abrir para um diálogo profícuo com seus educandos e ressaltar seu papel de mediador nesse processo.

Por fim, apesar dos limites do escopo desta revisão e do contexto das publicações encontradas, entendemos que existe a necessidade de aprofundamento dos estudos que aproximem o campo das teorias da comunicação e da linguagem em relação ao uso das tecnologias audiovisuais no campo da docência e da educação. Esse aprofundamento se faz necessário no sentido de contribuir para a pesquisa e a própria docência no campo das mídias sociais digitais aplicadas aos processos de ensinar. Para tanto, é preciso fomentar políticas públicas para o planejamento de ações de infraestrutura de acesso à internet com qualidade, aos recursos tecnológicos para a produção audiovisual e a formação inicial e continuada de professores, a fim de que possam emergir novas estratégias para a autoria docente e discente, no sentido de fortalecer o protagonismo de professores e dos alunos em seus percursos formativos.

\section{Referências Bibliográficas}

BISPO, L. M. C.; BARROS, K. C. Vídeos do YouTube como recurso didático para o ensino de história. Atos de Pesquisa em Educação, Blumenau, V.11 n³, p. 856-877, 2016.

BORGES, M. K.; KAMIGOUCHI, T. Do YouTube à escola: transformações nas práticas docentes dos professores de história, provocadas pelo acesso de estudantes a conteúdos de história veiculados por youtubers. Media Education 11.1, p. 37-46, 2020.

BRITO SILVA, J. Plataforma YouTube como ferramenta para o ensino de biologia. Estado do Mato Grosso: Cuiabá: Instituto de Biociências/UFMT, 2019. 131p. Dissertação de mestrado. 
COELHO, F. M. T. D. S.; BOTTENTUIT JUNIOR, J. B. O YouTube como instrumento de estímulo ao processo de aprendizagem nas universidades. Revista Intersaberes, Curitiba V.14 n³1, p. 20-36, 2019.

DE MELLO SOUZA, M.; DA SILVA VILELA, G.. Videoaulas de Ciências no YouTube como ferramenta educacional para o ensino fundamental na pandemia de Covid-19. Congresso Nacional de Pesquisa e Ensino em Ciências - V Conapesc, 2020.

JUNGES, D.; GATTI, A. Estado da arte sobre o YouTube na educação. Revista Informação na Cultura, Mossoró, V.1 Nº 2, p. 113-131, 2019.

KAMIGOUCHI, M; BORGES, M. Professores e YouTube: possibilidades e desafios para o ensino de história na era da cultura digital. In: Colóquio Luso-Brasileiro de Educação - COLBEDUCA. Florianópolis. Anais. Florianópolis: UDESC e UMINHO, 2017, p.0103.

NETO, J. O. R.; DE SÁ, J. P.. Ensino de História e educação não formal: o fenômeno das videoaulas do YouTube. Tecnia, Goiânia v. 4, n. 1, p. 170-184, 2019.

OLIVEIRA, J. Educação histórica e Aprendizagem da "História Difícil" em vídeos no YouTube. no Estado do Paraná. Curitiba: UFPR, 2016, p 120. Dissertação de mestrado.

OLIVEIRA, P. P. M. O YouTube como ferramenta pedagógica. In: SIED Simpósio Internacional de educação à distância/EnPED Encontro de pesquisadores de educação à distância. São Carlos. Anais. São Carlos: UFSCAR, 2016, p. 01-14.

PAULO, P. Produção de videoaulas como materiais didáticos inclusivos para professores de química do Ensino Médio. Rio de Janeiro. Niterói: UFF 2017 p. 84. Dissertação de Mestrado.

PECHANSKY, R. O. YouTube como plataforma educacional: reflexões acerca do canal Me Salva. In: XVII Congresso de Ciências da Comunicação na Região Sul, Porto Alegre. Anais. Porto Alegre: Intercom Sul, 2016, p. 1-13.

ROSKOWINSKI, R. Reflexão sobre os anúncios publicitários veiculados no YouTube e sua importância nas aulas de Língua Portuguesa. São Paulo. Taubaté: Universidade de Taubaté 2016 p. 139. Dissertação de Mestrado.

QUEIROGA JÚNIOR, T.; DULCI, T. "Professores-Youtubers: análise de três canais do YouTube voltados para o ensino de História. Escritas Do Tempo, 1(1), 04-29, 2019.

QUINTANILHA, L. F. Inovação pedagógica universitária mediada pelo Facebook e YouTube: uma experiência de ensino-aprendizagem direcionado à geração-Z. Educar em Revista. Curitiba, v. 33 n 65 p. 249-263, 2017.

REBELO, B.; CARVALHO, T. YouTube como ferramenta de apoio no ensino nãoformal do inglês. Internet Latent Corpus Journal, Portugal, v. 7, n. 2, p. 5-16, 2017.

SANTAELLA, L. Comunicação ubíqua: Repercussões na cultura e na educação. São Paulo: Paulus, 2013 p.376 
SANTAELLA, L. O leitor ubíquo e suas consequências para a educação. Complexidade: redes e conexões na produção do conhecimento. Curitiba: p. 27-44, 2014.

SANTANA, C. Produção de vídeo estudantil como estratégia para aprendizagens matemáticas. Bahia. Vitória da Conquista 2018, p.140. Dissertação de Mestrado.

SILVA, M. J.; PEREIRA, M. V.; ARROIO, A. O papel do YouTube no ensino de ciências para estudantes do ensino médio. Revista de Educação, Ciências e Matemática, Rio de Janeiro, v. 7, n. 2, 35-55 p. 2017.

SILVA, M. O uso de vídeos no ensino de ciências: o papel do YouTube para estudantes do ensino médio. no Estado do Rio de Janeiro. Rio de Janeiro: IFRJ, 2017. p. 74. Dissertação de Mestrado.

SILVA, M. P. YouTube, juventude e escola em conexão: a produção da aprendizagem ciborgue. no Estado de Minas Gerais. Belo Horizonte: UFMG 2016 p.172. Dissertação de Mestrado.

SOUZA, C; FERREIRA, J; PEREIRA, A; SILVA, M. Entendendo o uso de vídeos como ferramenta complementar ao ensino. Journal of Health Informatics. São Paulo. V. 11 n. 01, 03-07 p., 2019.

\footnotetext{
[a] O presente trabalho foi realizado com apoio da Coordenação de Aperfeiçoamento de Pessoal de Nível Superior - Brasil (CAPES) Código de Financiamento 001.

This study was financed in part by the Coordenação de Aperfeiçoamento de Pessoal de Nível Superior - Brasil (CAPES) - Finance Code 001 .

[b] Prossumidor (prosumer) é um termo criado por Alvin Toffler no livro “A Terceira Onda” (1980), que conjuga as palavras produtor e consumidor.

${ }^{[c]}$ Em seu livro “A fábrica de cretinos digitais" o neurocientista Michel Desmurget apresenta dados que demonstram que pela primeira vez na história os filhos apresentam QI inferior ao de seus pais. O autor ressalta que não se pode afirmar de forma definitiva que o aumento do tempo diante de telas seja o único fator responsável dessa diminuição, mas cita diversos estudos que indicam que o excesso de tempo em telas em detrimento da diversidade de outras experiências limita o desenvolvimento cognitivo.
} 